\title{
A Methodological Approach to Dematerialization of Business Processes Using Open-Source Technology
}

\author{
Liliana Ávila \\ PhD Student, DEGEI, Universidade de Aveiro, 3810-193 Aveiro, Portugal, liliana.avila@ua.pt \\ Leonor Teixeira \\ Assistant Professor/Researcher, DEGEI / IEETA, Universidade de Aveiro, 3810-193 Aveiro, Portugal, Iteixeira@ua.pt \\ Pedro Almeida \\ PhD Student, DEGEI, Universidade de Aveiro, 3810-193 Aveiro, Portugal, pma@ua.pt
}

Received (22.11.2016.); Revised (15.03.2017.); Accepted (19.10.2017.)

\begin{abstract}
Projects of dematerialization of business processes allow organizations to modernize their administrative activities through the rationalization and optimization of information flows and elimination of documents circulating in paper format. In this article is proposed a methodology for the implementation of projects of dematerialization of business processes in public and private organizations constituted by four stages: preliminary studies and requirements elicitation, modelling, construction and transition. It is also described a pilot-experience in a public entity using an opensource software (Bonita Open Solution) in order to validate the proposed methodology and confirm open-source technologies as a good option to implement this type of projects in a low-cost approach. Furthermore, throughout the paper, some guidelines are provided based on critical success factors and tools to support development stages.
\end{abstract}

Key words: dematerialization of business processes, methodology, open-source software, workflow management

\section{INTRODUCTION}

Increasingly, organizations seek to optimize their processes as a way to increase their competitiveness in the market and improve their results. In this context, it is important to find new ways to improve efficiency within organizations. Dematerialization of business processes (DBP) emerges as one of the solutions by offering new approaches to production, organization, circulation and retrieval data and information through Information and Communication Technologies (ICT). This type of technological solution promotes clear, structured and transparent processes, especially when problems are associated with paper-based documents. Projects of DBP are based on the principle of rationalization and optimization of information circuits through workflow management technologies. Additionally, the information is stored and communicated in a digital format to simplify its exchange and future monitoring. The increase in productivity, which often results from the implementation of DBP, comes from the decrease in the amount of time to perform the tasks, the effectiveness of human resources attached to those tasks, the quick access to information, and also from the improvement in communication flow between different services associated with the dematerialized process.
The implementation of this type of projects requires the identification of data circuits, information flows and needs, types of documentation and the responsibilities associated to each task, in order to readjust the information flow, simplify and rationalize procedures.

Experiences reports and methodological approaches to implement DBP are themes not yet explored in the literature. However, this concept is already popular in some domains, especially associated to the modernization of public administration. Few organizations benefit from the modernization of their services taking advantage of this type of solution autonomously and without contracting outsourcing services. Each company adopts its own methodology, due to the lack of a common framework.

The main purpose of this paper is to present a methodology and some guidelines for the implementation of projects of DBP in order to support public and private organizations in the process of administrative modernization of their services using open-source technologies.

The information presented was based on the literature review, focusing on topics such as "workflow management systems", "electronic documents management" and "information systems development". In order to validate the stages of the methodology, 
people involved in projects of DBP in two different public entities were interviewed. These interviews were complemented with visits to those organizations. Finally, the implementation of a pilot experience in a public entity, using an open source technology, allowed the validation of some operational activities of the proposed methodology.

The article is structured in four sections. Section 2 presents the concepts related with DBP, their advantages, disadvantages and critical success factors for the implementation of such projects. Section 3 presents the proposed methodology, the different stages that constitute it and some supporting tools. Section 4 describes the application of the proposed methodology in a pilot experience in a public institution, using open-source software (Bonita Open Solution). In the final section the main conclusions of the developed work are presented.

\section{ABOUT DEMATERIALIZATION OF BUSINESS PROCESSES}

In this section, an overview of the literature will be provided. As this is an unexplored theme, first, the concept of DBP will be clarified based on the recent work developed in related domains as the workflow management systems and processes reengineering and some 'pros and cons' will be presented. After that, in section 2 will be identified some aspects that can contribute for the successful implementation of such projects, denominated in the literature as critical success factors.

\subsection{Advantages and disadvantages of dematerialization of business processes}

Dematerialization of business processes refers to the optimization of information circuits through technological applications, where the information is stored and communicated in digital format in order to expedite and facilitate the monitoring of processes, always ensuring the electronic documents legal value.

Closely related to this topic arise concepts as Workflow Management Systems and Business Process Reengineering. Workflow Management Systems are defined as generic software packages that support the management of business processes, taking into account its information logistics. This type of system ensures that the right information is given to the right person, at the right time [1].

On the other hand, experts in the field of reengineering defined this concept as the rethinking and redesign of business processes, in order to achieve significant improvements in key performance indicators as, for example, costs, quality, service and speed [2].

Although a dematerialization project involve processes reengineering, when successfully carried out can potentiate several advantages. Among those advocated by researchers that work in this field, can be highlighted the fact that DBP enables the conclusion of tasks more efficiently [3], the elimination of redundancies and unnecessary tasks $[4,5]$, the standardization of procedures $[5,6]$ and access to data from any geographic location $[5,6,7,8]$. This allows savings in time and costs $[3,4,5,6,7,8,9]$, as well as improving the quality of processes and their outcomes $[3,5,6,7]$. Some researchers argue that this type of projects could help to improve communication between collaborators $[5,7,8,10]$.

However, as are usual in technology-based projects, there are some 'cons' (disadvantages). In a first instance, a dematerialization project involves a slow and gradual implementation process $[7,11]$ and an substantial initial investment [7], that may be seen by organizations as obstacles to its adoption. The existence of a break in performance and workers instability due to greater control by the managers $[4,5$, 6 , 12] also appear as consequences of the dematerialization project and a barrier to its acceptance. In Figure 1 are presented some more advantages and disadvantages (cons) identified in literature related to such projects.

In the next section are presented some critical success factors identified in the literature that could be important take into account during the implementation of projects of DBP.

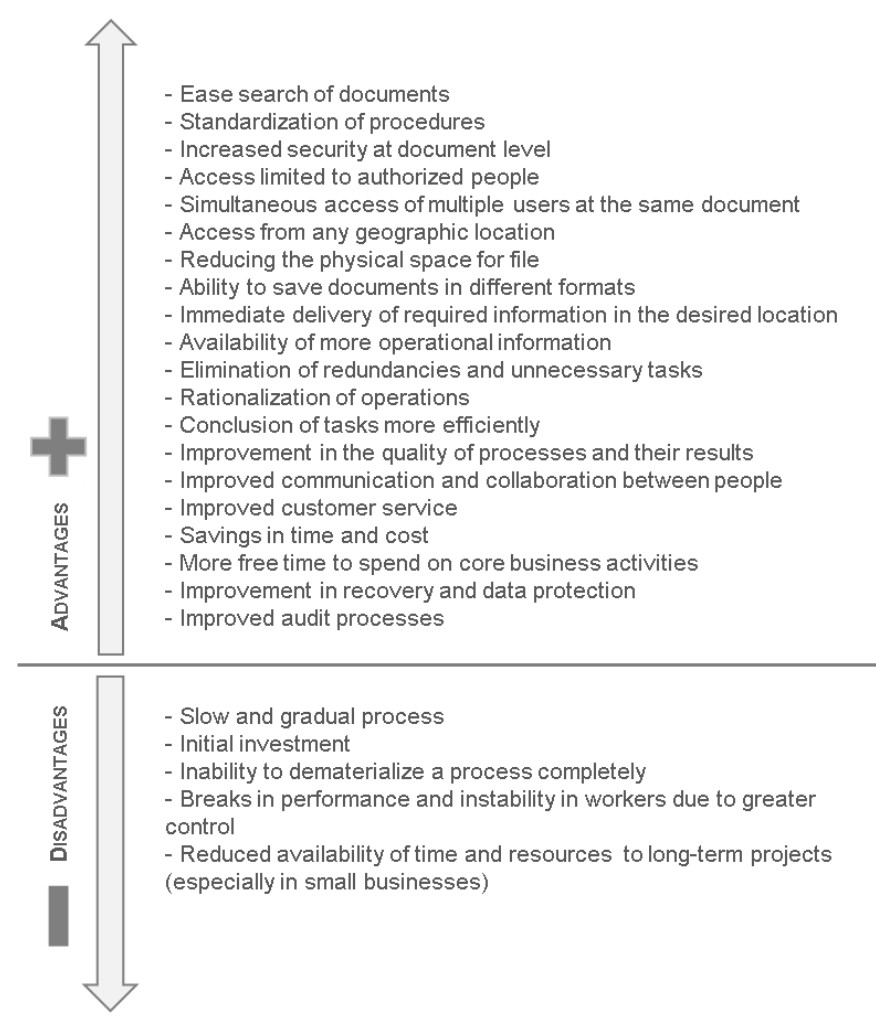

Figure 1. Advantages and disadvantages of DBP.

\subsection{Critical Success Factors}

Any element that can present itself as a facilitator in the implementation of a project is defined in the literature as a Critical Success Factor (CSF). In order to identify these factors in projects of DBP, some work conducted in the field were analyzed.

The success of such projects within an organization may depend on several factors, which in general are 
categorized into organizational and technological factors.

Organizational factors are those related to the organization and its employees. The success of the project can be conditioned by the type of culture and the learning capacity of the organization. It is important to promote a culture of change, for a faster adaptation to new variables that can be introduced in work routines $[6,12,13,14,15]$.

Another factor pointed by several authors is the need for strong leadership or someone who has the power to influence the decision maker. It is crucial that the decision to implement dematerialization projects is taken by administrative managers, once in that case the employees will be more open to collaboration $[6,12,13$, $14,15,16,17,18]$. However, some additional mechanisms may be used to involve all stakeholders as reward systems and empowerment [13, 14, 15]. A good practice is the establishment of a multidisciplinary project team, including employees from different departments for promoting the integration of different perspectives [14, 16, 18].

In addition, training of employees is another key factor for a successful transition to a dematerialized environment [13, 14, 15, 16, 18]. In many organizations there is a strong resistance to change. It is crucial to explain to the employees the importance of the change in their working practices and the added value of the development of new skills. They should also be aware of a possible decrease in productivity immediately after the implementation of the system, while some adjustments are made to adapt the new processes to the organization [12].

One of the secrets to achieve a fully dematerialized environment is the adoption and use of the implemented technology by all stakeholders, in order to cover all the value chain [11]. Many organizations that make a significant investment in online applications still receiving many documents in paper format because their stakeholders do not follow the project. The organization must communicate them (suppliers, customers) its new capabilities, their benefits to the value chain in which they are included and provide the necessary support and training [18].

Another relevant aspect is the alignment between the strategy that is followed by the organization and the one that is associated with the project of DBP [12, 13, 14, $15,16]$. However, it is not always possible to respond to individual requirements instead of the correct operation of the system as a whole.

In addition to the CSF related to the organizational environment there are some aspects related to the project itself. First, there are the fitness of the methodology [13, 14, 15], techniques and tools applied during the implementation [13, 14]. It is also important to ensure that the selected team has the knowledge to make the best choices. Sometimes, it can be very beneficial to seek consulting services to access specialized know-how and integrate in the team people that already have expertise in such projects [14, 18].

Before starting the project, benchmarking can be used as a way to become aware of what really is DBP, their key benefits, learn from the success achieved and mistakes that were committed by other organizations. Higher previous knowledge about the subject, higher is the probability that it will be successfully implemented. A budget to the project execution should be defined, based on the analysis of available resources and expected costs [14, 15, 16, 18]. Finally, it is essential the establishment of goals and performance indicators to evaluate the results and the success of the project $[13,14,18]$.

On the other hand, there are the technological factors. The right choice of software and hardware is one of those which can contribute to a successful implementation $[14,16,17,18]$. However, it should also be noted the need to assure that the acquired technology is used effectively by the stakeholders [12, $13,14,15,17,18]$ and that there is a concern with a good integration with existing systems [14, 16, 18].

Figure 2 shows the key CSF identified in the categories of organizational and technological factors.

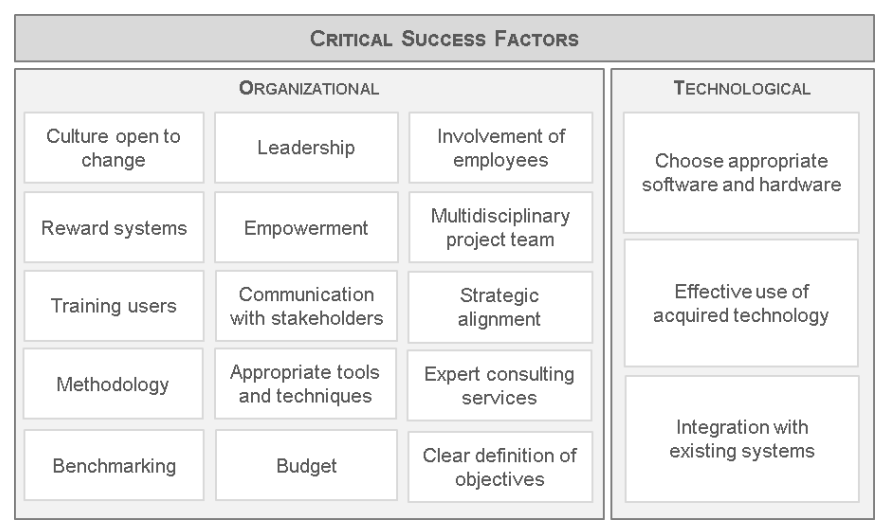

Figure 2. Critical success factors for processes dematerialization.

In the next section, will be presented a methodological approach to DBP, describing their main stages and some supporting tools that can be used in each of them.

\section{A METHODOLOGICAL PROPOSAL TO DEMATERIALIZATION OF BUSINESS PROCESSES}

The development of a project of DBP follows a set of stages similar to a project of information system development since it implies the adaptation of one technology to a specific context.

The development of information systems includes several steps that can be classified as requirements analysis, processes modelling, implementation and deployment [19]. In a case of project of DBP it is possible to identify four important main stages: preliminary studies and requirements elicitation, modelling, construction and transition. For each one of them were identified some supporting tools, presented at Figure 3. In the next four subsections will be defined in more detail the different stages that constitute the proposed methodology and suggested some tools that can support the work at each stage. 


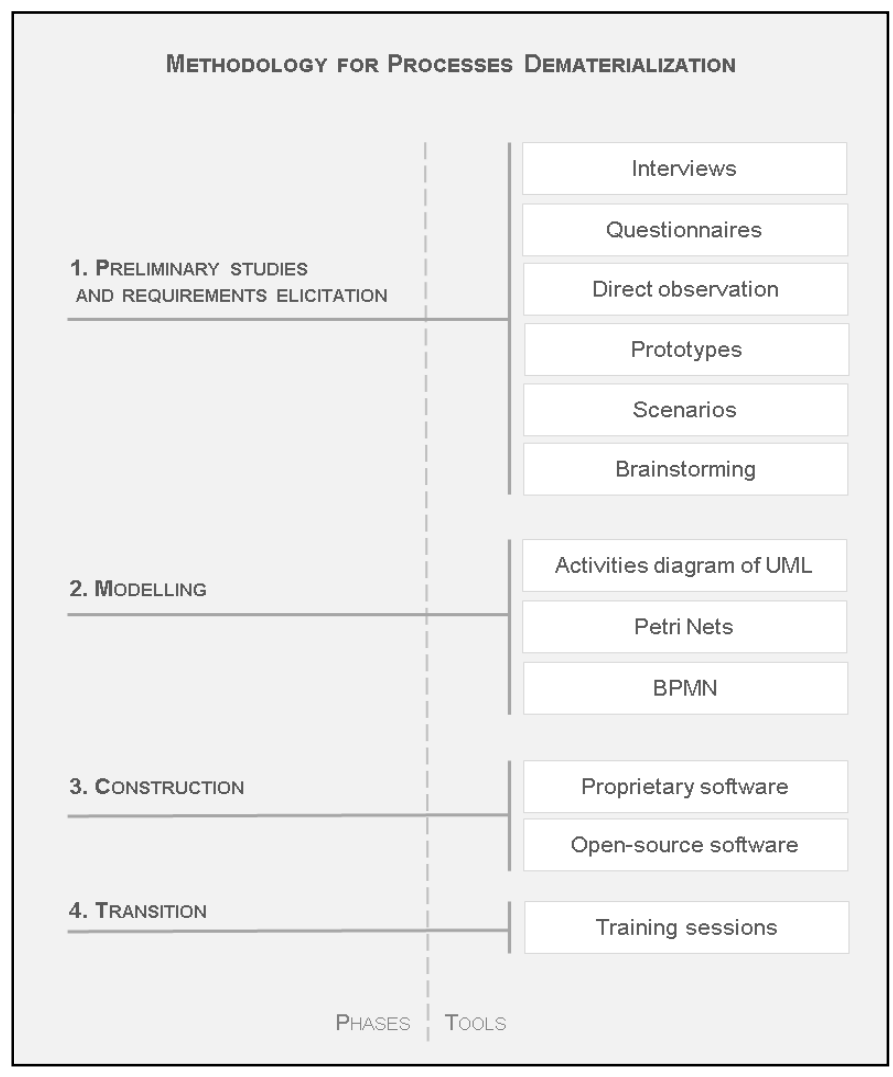

Figure 3. Proposed methodology for the implementation of processes dematerialization project.

\subsection{Preliminary studies and requirements elicitation}

The preliminary study stage and requirements elicitation puts the emphasis on aspects related to the business model and requirements elicitation.

Whatever the type of project, is always important to understand the organization's dynamics in which it will take place.

This knowledge will help to identify current problems and domains where the redesign and processes reengineering is a priority in order to optimize outputs. It is also at this stage that we evaluate the motivation of top management to these issues, the availability of resources such hardware and software (physical resources), know-how (intellectual resources), openness to collaboration (human resources), budget (financial resources), and the identification of key stakeholders for requirements gathering.

There are some techniques that can be used for requirement elicitation, such as interviews, questionnaires, direct observation or some more recent techniques as prototypes, scenarios and brainstorming sessions [20].

Once collected the main requirements of stakeholders (eventually some more will be recognized during the project), these should be carefully analysed and validated taking into account the analyst understanding of business processes. That is the modelling phase.

\subsection{Modelling}

The modelling phase puts the emphasis on the analysis and modelling of processes. The analysis and validation of requirements is essential because each stakeholder looks to processes in a different way, so it is possible that there are incompatibilities between requirements indicated by different people. Therefore, it is important to have good judgment, trying as far as possible to meet the expectations of users, always keeping in mind the project goals.

When completed the analysis and validation of requirements, it is time to define the processes to automate. Sometimes due to the inefficiency of current procedures it is necessary a deepest change that implies a processes reengineering, as mentioned above. The description of simple processes can be made textually. However, when they assume greater complexity is more difficult their understanding and more likely make some mistakes. In this case, this description should be followed by a diagram to facilitate their interpretation, both by analysts and end users [21]. There are some tools used on processes modelling, such as the activity diagram of UML (Unified Modelling Language), an object-oriented notation [22], the Petri nets, which have a simple and intuitive notation with the possibility of converting models into execution language [1], and the Business Process Modelling Notation (BPMN), which takes the lead in business processes and workflow modelling, a standard adopted by the Object Management Group (OMG) [21, 23].

At this stage, we already have a representation of the processes to dematerialize, validated by stakeholders. The next step is their automation, using a technology that allows the workflow and documents management.

\subsection{Construction}

At this point, the most important activities are the choice of the technology and its parameterization. Here, the organization has many possibilities. If is a large organization that as a department fully dedicated to the development of information technology (IT), possibly it will make use of its resources and decide for the internal development of the application that will support DBP. Smaller companies that do not have the same resources generally choose other solutions, as the outsourcing of all or part of the technology development or the recruitment of external consultants who provide the necessary support to the company's employees.

However, currently in the software market are available a wide range of technologies that can be adapted to different contexts and allow the decrease in the necessary budget and other resources. In the selection of an existent application, the choice may fall on proprietary or open-source software. Lately they have been great advances in the field of open-source, becoming an alternative increasingly sought, due the low cost associated and its satisfactory quality [24]. Table 1 shows the results of a study performed on some existing market solutions in order to determine an attractive alternative to the implementation of such projects, where different solutions are evaluated 
according to some criteria identified as relevant. It is noted, however, that this comparative study was only based on information accessible via the official website of the respective providers.

From the analysis of Table 1, we conclude that some of these solutions give higher importance to features targeted for workflow management, while others highlight more features related to the document management. In general, and as expected, proprietary software provides a more complete set of features. However, given the advantages of open-source software, the range of features they offer should not be neglected, including the Activiti and Bonita Open Solution. Thus, they can be an alternative recommended for smaller organizations or for those wishing to make a first approach to DBP, testing its use in a restricted set of processes.

Table 1. Comparative study of software to support the implementation of dematerialization of business processes.

\begin{tabular}{|c|c|c|c|c|c|c|c|c|c|}
\hline \multirow[b]{2}{*}{ Features } & \multirow{2}{*}{ Software type } & \multicolumn{3}{|c|}{ Proprietary } & \multicolumn{5}{|c|}{ Open-source } \\
\hline & & [1] & [2] & [3] & [4] & [5] & [6] & [7] & [8] \\
\hline Design workflows with BPMN & & $\bullet$ & & $\bullet$ & $\bullet$ & & $\bullet$ & & $\bullet$ \\
\hline Process simulation & & • & & & & & - & & \\
\hline Process optimization & & • & & - & $\bullet$ & & & & • \\
\hline Model repository & & $\bullet$ & & - & $\bullet$ & & - & & \\
\hline Web forms designer & & $\bullet$ & $\bullet$ & $\bullet$ & & & $\bullet$ & & $\bullet$ \\
\hline Client-server architecture & & $\bullet$ & & $\bullet$ & & • & $\bullet$ & • & \\
\hline Software in the cloud & & $\bullet$ & & $\bullet$ & $\bullet$ & & & & • \\
\hline Notifications & & $\bullet$ & & & & $\bullet$ & & • & \\
\hline Monitoring activities & & $\bullet$ & & $\bullet$ & $\bullet$ & & & & \\
\hline Management users & & & • & $\bullet$ & • & & - & - & $\bullet$ \\
\hline Reports & & - & $\bullet$ & $\bullet$ & $\bullet$ & & • & $\bullet$ & \\
\hline Digital signature & & & - & & & & & $\bullet$ & \\
\hline Collaboration tools & & - & & & & • & - & & \\
\hline
\end{tabular}

Label: [1] Appian; [2] FileDoc; [3] RunMyProcess; [4] Activiti; [5] Alfresco; [6] Bonita Open Solution; [7] iPortalDoc; [8] ProcessMaker

\subsection{Transition}

To complete the cycle, there is a transition phase, when the system is ready to be used by the end user and is introduced into the real work context. During the adaptation should be provided all the necessary assistance to the users until they are able to take full advantage of the new tool and not recognize the existence of obstacles to perform their work. It could also be useful to provide some training sessions to end users. This point is decisive to determine if the project was completed successfully or not. All the work done previously is useless if at this stage there is not a good acceptance by the end user. Some performance indicators should be established to assess with accuracy the results obtained with the project and determine if it was successfully implemented.

The methodology presented in this chapter was applied in practice through a pilot experience in a public entity, described next.

\section{A PILOT EXPERIENCE OF DEMATERIALIZATION OF BUSINESS PROCESSES IN A PUBLIC INSTITUTION}

The proposed methodology was tested in practice through a pilot experience that took place in a public institution. The main purpose of this experience was to make the selected processes more efficient and less dependent on the circulation of paper, clarifying the responsibilities of each intervenient in each task, testing at the same time the potential use of open-source technologies in this context.

Before starting the pilot we tried to identify some CSF in two institutions of public administration that had already implemented or being implementing DBP projects. These two organizations were selected because they have experienced different practices in the implementation of dematerialization projects. The benchmarking study was based on interviews, complemented with a visit to the local.

One of the studied entities began its project of DBP in 2008, and did not complete the project until the day of the interview ( 3 years after the beginning). The existence of some difficulties in the project that have contributed to its failure was evident. On the other hand, the other entity studied is a case of reference, recognized by many of its partners and peers as a successful example of a DBP project.

Differences between these two institutions were identified that may have contributed to the project failure or success and eight CSF were recognized: (a) Culture open to change, (b) Leadership, (c) Involvement of employees, (d) Multidisciplinary project team, (e) Budget, (f) Choose appropriate software and hardware, (g) Effective use of acquired technology and (h) Integration with existing systems.

Evidences found in each one of the entities are briefly described in Figure 4. 


\begin{tabular}{|c|c|c|}
\hline & EVIDENCE IN ENTITY 1 & EVIDENCE IN ENTITY 2 \\
\hline (a) & $\begin{array}{l}\text { Lack of communication and } \\
\text { coordination between the } \\
\text { different departments. }\end{array}$ & $\begin{array}{l}\text { The employees accept the change as } \\
\text { an inevitable way to improve the quality } \\
\text { of services provided by them. }\end{array}$ \\
\hline (b) & $\begin{array}{l}\text { The project began with strong } \\
\text { support from a person of the } \\
\text { executive but with his departure } \\
\text { it was abandoned. }\end{array}$ & $\begin{array}{l}\text { The initiative for the implementation of } \\
\text { the project came from the mayor. }\end{array}$ \\
\hline (c) & This factor was not identified. & $\begin{array}{l}\text { Regularly, representatives of different } \\
\text { departments improvements in } \\
\text { information flows with the support of IT } \\
\text { staff to clarify doubts. }\end{array}$ \\
\hline (d) & $\begin{array}{l}\text { No exists coordinator or team } \\
\text { designated for the project. }\end{array}$ & $\begin{array}{l}\text { Along the process there was a great } \\
\text { involvement of the mayor, the technical } \\
\text { support from the software company } \\
\text { and the collaboration of people from } \\
\text { various departments. }\end{array}$ \\
\hline (e) & $\begin{array}{l}\text { It was not considered the } \\
\text { budget required for the } \\
\text { acquisition of hardware. }\end{array}$ & $\begin{array}{l}\text { Initially, were taken into account the } \\
\text { costs related to the acquisition of the } \\
\text { software and hardware required for the } \\
\text { full operation of the system. }\end{array}$ \\
\hline (f) & $\begin{array}{l}\text { The entity was already a } \\
\text { customer of the software } \\
\text { company. }\end{array}$ & $\begin{array}{l}\text { The entity was already a customer of } \\
\text { the software company }\end{array}$ \\
\hline (g) & $\begin{array}{l}\text { The features of the system are } \\
\text { underused due to the lack of } \\
\text { resources and resistance of } \\
\text { some employees to change. }\end{array}$ & $\begin{array}{l}\text { There is a concern with the } \\
\text { improvement of the system, namely by } \\
\text { updating the processes models in } \\
\text { order to be as functional as possible. }\end{array}$ \\
\hline (h) & $\begin{array}{l}\text { There is a lack of integration } \\
\text { between ERP modules. }\end{array}$ & $\begin{array}{l}\text { There is concern about the integration } \\
\text { with existing system, as a way to } \\
\text { eliminate the repetition of tasks and } \\
\text { simplify the execution of tasks. }\end{array}$ \\
\hline
\end{tabular}

Figure 4. Critical success factors for DBP and respective evidences in Entity 1 and Entity 2.

The study of these two realities was the starting point to the implementation of the pilot experience. This experience took place in a division of a public higher education institution. Most of the documentation in this division is stored in paper format and the information circulated by email between the different actors. Sometimes, this information did not follow the route that would be expected or there were delays in the performing of tasks. The need to clearly define processes and the role of each actor were the reasons identified for the implementation of a DBP project.
In a first instance (Preliminary studies and requirements gathering), was considered appropriate evaluate some documentation and talk with employees in order to identify priority processes for implementation, their respective tasks, information and communication flows. At this stage, some techniques, like direct observation, document analysis and unstructured interviews, were applied.

Based on the collected data, models were defined using the BPMN (Modelling). This notation was easily understood by users that were involved in the validation of models, thus confirming it as a right choice.

The cycle of 'validation - redesign' of the models had several iterations and was concluded when the consensus between all parts was achieved. Figure 5 presents an example of one process modelled using BPMN.

Next, it was time to automate processes using software for document and workflow management (Construction). Here was essential the choice of technology as advocated in the literature. The decision was based on the results of the analysis already performed and presented at Table 1.

For this pilot experience, was determined that would be used an open-source software in order to assess the potential of open-source technologies for DBP projects. This requirement limited the choice to Bonita Open Solution, Process Maker and Alfresco. In the first two cases, the software was installed and in the third one the evaluation was done through the analysis of the trial version, available in the website for download. After analysing the main interfaces of each alternative, it was decided to choose the Bonita Open Solution (BOS 5.6) for application to the practical case for being the one who seemed to be the most user-friendly and that had a more intuitive and appealing interface. After that, Bonita Open Solution was parameterized according to the requirements collected previously. One of the processes dematerialized was the work related to the "jury appointment for defense of the MSc dissertation", Figure 6.

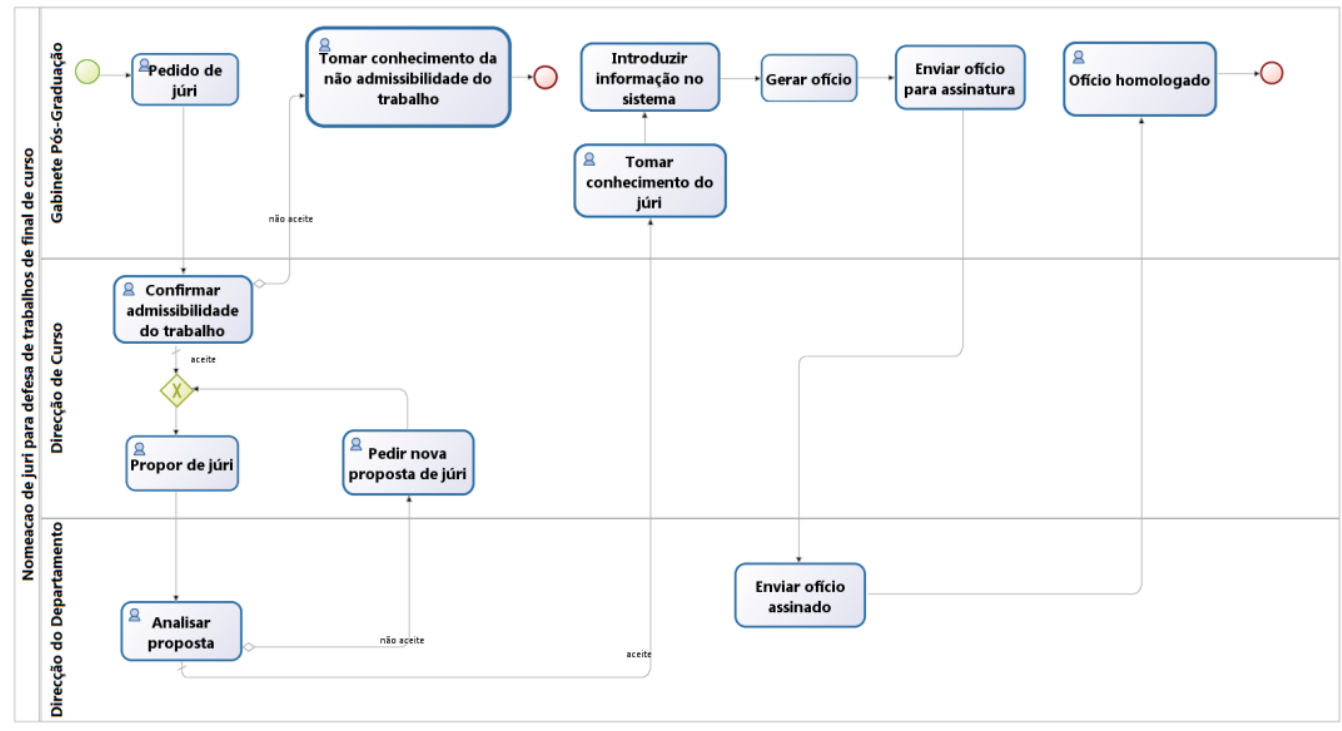

Figure 5. Example of a process modeled with BPMN (in Portuguese). 


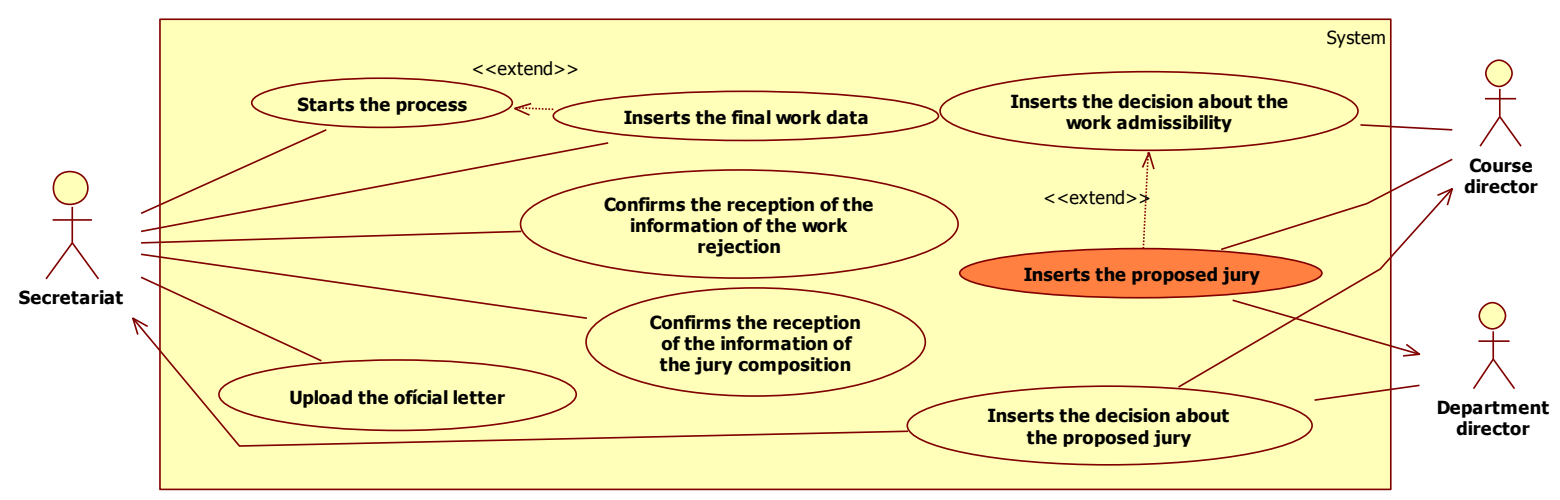

Figure 6. Use-cases diagram of the process “ jury appointment for defense of the MSc dissertation”.

Figure 6 shows the Use-Case diagram of UML with the funcionalities of the system and Figure 7 presents examples of two possible interfaces of Bonita Open Solution to the introduction of information in the system for the use-case "Register the jury proposed".
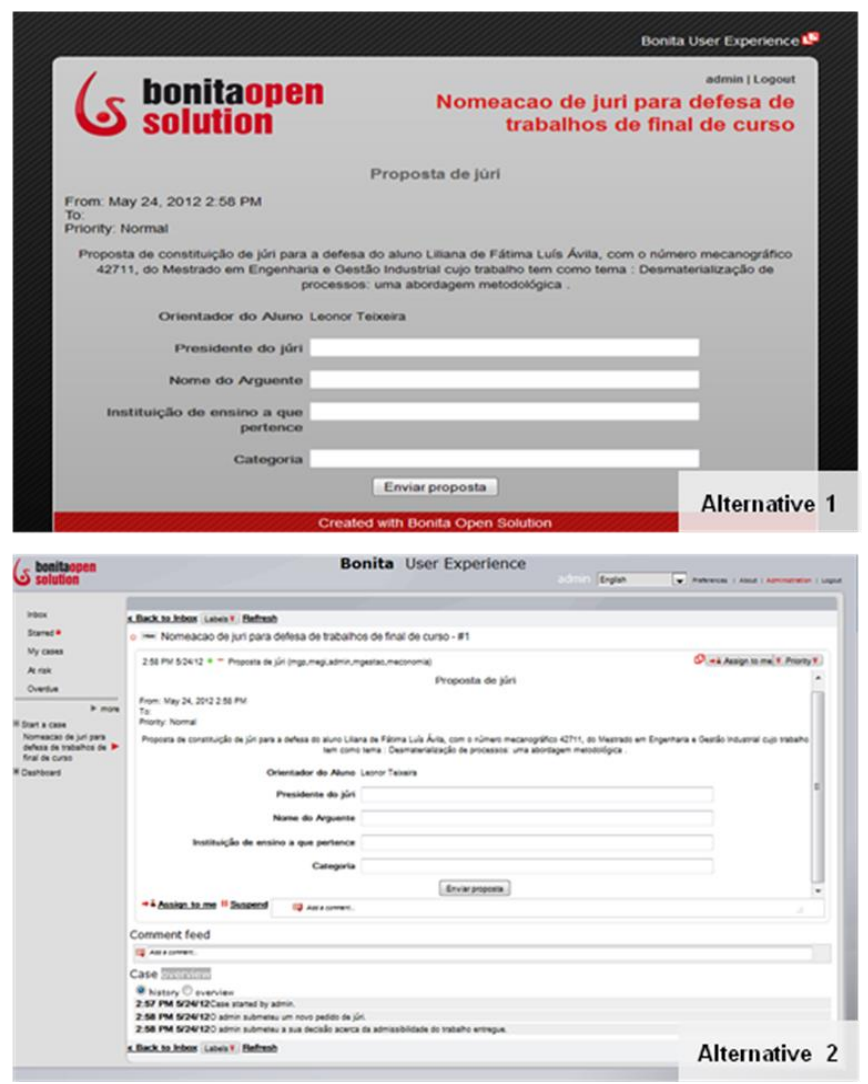

Figure 7. Interfaces of Bonita Open Solution for the use-case "Register the proposal of jury" (in Portuguese).

Before the introduction of the prototype in the workplace, a demonstration of the system was made. This is another mechanism that can be used to validate the requirements defined in previous phases and to identify possible improvements to be included in the system before the transition phase.

\section{CONCLUSION}

Dematerialization of business processes represents a solution to problems related to the existence of documentation in paper format, common to most of organizations. It enables improvements in performance through workflow management.

The success of a DBP project strongly depends on the initiative of top management, the culture of the organization and the efforts made to encourage the participation of employees.

On the other hand, from the technological point of view, it is important the choice of technology, the promotion of its use in an efficient way and ensure its integration with existing systems. It is also important to the success of the project the definition of a methodology and the use of appropriate supporting tools.

The methodology to be adopted in the implementation of these projects is similar to that used in the development of information systems, as well as the tools that can support the implementation process. Each one of the phases that constitute the proposed methodology was defined and was described a pilot experience of DBP in a public institution. Its main purpose was make the selected processes more efficient and less dependent on the circulation of paper, clarifying the responsibilities of each intervenient in each task, testing at the same time the potential of use open-source technologies in this context.

Regarding the technological offer for implementing dematerialization projects it is concluded that, although the most complete solutions are proprietary ones, open source technologies now occupy a prominent position, offering low-cost solutions with a set of features that respond to the needs of most organizations that seek new approaches to production, organization, distribution and retrieval of information based on the redefinition of processes and information flows.

On the other hand, the benchmarking was considered a useful tool to understand the critical success factors of a DBP project once it promotes learning and identification of best practices through the study of other experiences or projects from similar contexts.

This work was based on an exploratory study, which focuses only on public entities. Further research is needed in order to better understand why this type of projects is less popular in private sector organizations. Moreover, it is also important to find a more consistent methodology and some indicators that would allow organizations to measure the success of their projects. 


\section{REFERENCES}

[1] Aalst, W. v. d. and Hee, K. v. (translated by Jorge Cardoso) (2009), Gestão de Workflows: Modelos, métodos e sistemas, Imprensa da Universidade de Coimbra, Coimbra, Portugal.

[2] Hammer, M., \& Champy, J. (1993), Reengineering the Corporation: A manifesto for business revolution, Harper Business, New York, USA.

[3] Johnston, G. and Bowen, D. (2005), "The benefits of electronic records management systems: A general review of published and some unpublished cases", Records Management Journal, Vol. 15, No. 3, pp. 131-140.

[4] Medina, R. and Fenner, J. (2005), "Controlling Your Documents: Consider the merits of starting out with straightforward document management as a way to socialize good document practices, providing a realizable path to electronic records management", The Information Management Journal, Vol. 49, No. 1, pp. 20-22.

[5] Rodrigues, J. (2010), "Sistemas de informação e gestão automatizada de processo: o impacto da sua implementação no Serviço de Estrangeiros e Fronteiras", Master's dissertation, Department of Social Sciences and Management, Open University, Lisboa, Portugal.

[6] Sarmento, A. (2002), "Impacto dos sistemas colaborativos nas organizações: estudo de casos de adopção e utilização de sistemas workflow", Ph.D. dissertation, Department of Information Systems, University of Minho, Guimarães, Portugal.

[7] Ashby, L. (2011), "Extension's Progress in the Paperless Revolution: Balancing Digital and Paper", Journal of Extension, Vol. 49, No. 1

[8] Want, C. (2009), "Bring Your Organisation up to Speed: The Benefits of Electronic Document Management", IDM (Information \& Document Management International), Vol. 59 pp.14.

[9] Schnitzer, E. (2010), "Paperless World", Multi-Housing News, Vol. 45, No. 2, pp. 33-34.

[10] Siatiras, K. (2004), "Electronic document management-why you need it", Chartered Accountants Journal, Vol. 83, No. 5, pp. 4-6.

[11] Burns, C. (2009), "Insurers Scale the Many Steps to Paperless", Insurance Networking News, Vol. 12, No. 8, pp. 14-18.

[12] Downing, L. (2006), "Implementing EDMS: Putting People First", The Information Management Jounal, Vol. 40, No.4, pp. 44-50.
[13] Alibabaei, A., Bandara, W. e Aghdasi, M. (2009), Means of achieving Business Process Management success factors, proceedings of the 4th Mediterranean Conference on Information Systems in Athens, Greece, Athens University of Economics and Business, paper 122.

[14] Al-Mashari, M. and Zairi, M. (1999), "BPR implementation process: an analysis of key success and failure factors", Business Process Management Journal, Vol. 5, No. 1, pp.87112.

[15] Paper, D. and Chang, R.-D. (2005), "The state of business process reengineering: a search for success factors", Total Quality Management \& Business Excellence, Vol. 16, No. 1, pp. 121-133.

[16] Alexander, A. (2009), "Going paperless: Starting on the same page", Accounting Today, Vol. 23, No. 13, pp. 22-28.

[17] MacQuarrie, B. (2004), "Digital Optimization", Sum News, Vol. 15 , No. 6 , pp. 22-24.

[18] Phelan, S. (2003), "A Paperless Success Story", Journal of Accountancy, available http://www.journalofaccountancy.com/Issues/2003/Oct/APaperl essSuccessStory.htm, (accessed: 20 may 2013).

[19] Avison, D. e Fitzgerald, G. (2003), Information Systems Development: Methodologies, Techniques and Tools, McGrawHill Education, New York, USA

[20] Gunda, S.G. (2008), "Requirements Engineering: Elicitation Techniques", Master's thesis, Department of Technology, Mathematics and Computer Science, University West, Trollätan, Sweden

[21] Ottensooser, A., Fekete, A., Reijers, H. A., Mendling, J. and Menictas, C. (2012), "Making sense of business process descriptions: An experimental comparison of graphical and textual notations", Journal of Systems and Software, Vol. 85, No. 3, pp. 596-606.

[22] Booch, G., Rumbaugh, J and Jacobson, I. (2005), The Unified Modelling Language User Guide, Pearson Education, New Delhi, India.

[23] Dijkman, R. M., Dumas, M. and Ouyang, C. (2008), "Semantics and analysis of business process models in BPMN", Information and Software Technology, Vol. 50, No. 12, pp. 1281-1294.

[24] Chester, B. (2006), "Open Source Document Management", AllM E-DOC, Vol. 20, No. 1, pp. 21-23.

\title{
Metodološki pristup dematerijalizaciji poslovnih procesa korišćenjem open source tehnologije
}

\author{
Liliana Ávila, Leonor Teixeira, Pedro Almeida
}

Primljen (22.11.2016.); Recenziran (15.03.2017.); Prihvaćen (19.10.2017.)

\begin{abstract}
Apstrakt
Projekti dematerijalizacije poslovnih procesa omogućavaju organizacijama da modernizuju svoje administrativne aktivnosti kroz racionalizaciju i optimizaciju tokova informacija i eliminaciju dokumenata koji kruže u papirnom formatu. $U$ ovom radu predložena je metodologija za realizaciju projekata dematerijalizacije poslovnih procesa u javnim i privatnim organizacijama u četiri faze: preliminarne studije $i$ elitiranje zahteva, modeliranje, izgradnja i tranzicija. Takođe, opisano je i pilot iskustvo u javnom entitetu koji koristi otvoreni izvorni softver (Bonita Open Solution) kako bi se potvrdila predložena metodologija, kao i tehnologije otvorenog koda kao dobra opcija za implementaciju ovakvih projekata sa nisko- troškovnim pristupom. Osim toga, u radu su prikazane određene smernice zasnovane na kritičnim faktorima uspeha $i$ alatima koji podržavaju prethodno identifikovane razvojne faze.
\end{abstract}

Ključne reči: dematerijalizacija poslovnih procesa, metodologija, softver otvorenog koda, upravljanje tokovima 